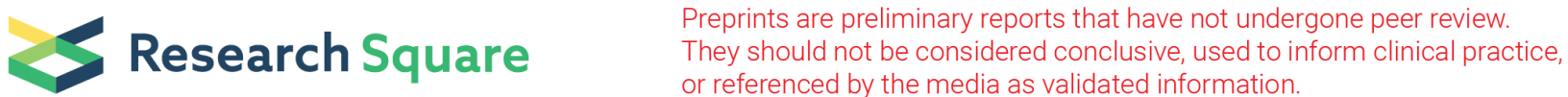 \\ Treatment patterns and Outcomes of Elderly Patients with Potentially Curable Esophageal Cancer
}

\section{Yang Yang}

Zhejiang University School of Medicine

\section{Mengyuan Chen}

Cancer Hospital of the University of Chinese Academy of Sciences (Zhejiang Cancer Hospital)

\section{Jiping Xie}

Yuyao People's Hospital

\section{Yongling Ji}

Cancer Hospital of the University of Chinese Academy of Sciences (Zhejiang Cancer Hospital)

\section{Liming Sheng}

Cancer Hospital of the University of Chinese Academy of Sciences (Zhejiang Cancer Hospital)

\section{Guoqin Qiu}

Chinese Academy of Sciences

\section{Xianghui Du}

Cancer Hospital of the University of Chinese Academy of Sciences (Zhejiang Cancer Hospital)

Qichun Wei ( $\nabla$ qichun_wei@zju.edu.cn )

Zhejiang University School of Medicine

\section{Research Article}

Keywords: esophageal cancer, treatment patterns, surgery, chemoradiotherapy, SEER

Posted Date: April 27th, 2021

DOI: https://doi.org/10.21203/rs.3.rs-443322/v1

License: (c) (i) This work is licensed under a Creative Commons Attribution 4.0 International License. Read Full License

Version of Record: A version of this preprint was published at Frontiers in Oncology on February 14th, 2022. See the published version at https://doi.org/10.3389/fonc.2022.778898. 


\section{Abstract}

Background: The proportion of elderly patients with esophageal cancer (EC) is increasing due to prolonged life expectancy and aging process. However, the optimal treatment strategy for elderly patients (aged $\geq 70$ years) with EC remains controversial.

Methods: Eligible patients with cT1b-4aNxM0 EC were identified in the Surveillance, Epidemiology, and End Results database from 2010 to 2016. Treatment patterns were divided into five groups: surgical resection (S), chemoradiotherapy (CRT), radiotherapy (RT), chemotherapy (CT), or observation with no treatment (Obs). Survival between groups was compared using the log-rank test, and the Cox proportional hazards model was used to identify factors associated with overall survival (OS).

Results: A total of 3233 patients with potentially curable EC were identified. Of all the patients included, 29.1\%, 48.2\%, 8.7\%, and 3.5\% received S, CRT, RT, and CT, respectively, whereas 10.5\% underwent Obs. The 3-year OS estimates were $45.8 \%$ ( $95 \%$ confidence interval [Cl]: 42.2-49.8\%), 26.1\% (95\% Cl: 23.5-28.9\%), 12.2\% (95\% Cl: 8.4-17.8\%), 14.9\% (95\% Cl: 8.4-26.4\%), and $6.7 \%(95 \% \mathrm{Cl}: 4.0-11.0 \%)$ for S, CRT, RT, CT, and Obs ( $\mathrm{p}<0.001)$, respectively. However, the survival benefits of surgery over CRT gradually weakened with the increase in age, and the survival benefit of surgery was statistically non-significant for EC patients aged $\geq 80$ years $(p=0.41)$. Multivariate analysis showed that treatment patterns, age, tumor grade, $T$ stage, $N$ stage, and marital status were significantly associated with OS.

Conclusion: Generally, the use of surgery was associated with the longest OS, and CRT was superior to RT or CT alone in elderly patients with curable EC. For patients intolerable to surgery or aged $\geq 80$ years, definitive CRT should be considered as a preferable option. The optimal treatment strategy for elderly patients with EC should consider comprehensive geriatric assessment, survival benefit, and patient preference in a multidisciplinary setting.

\section{Background}

Esophageal cancer (EC) is one of the most common cancers worldwide. Moreover, 604,100 people were newly diagnosed with EC, whereas 544,076 people died of EC in 2020, according to Global Cancer Statistics[1]. The peak age of EC incidence is between 60 and 70 years, and the incidence of EC decreases with age. According to the Global Burden of Disease report, approximately $30 \%$ of all newly diagnosed patients with EC are older than 70 years[2]. The proportion of elderly patients with EC will increase gradually in the future due to prolonged life expectancy and aging process. However, evidence concerning treatment strategies in elderly patients with EC is still inadequate, since most data are from clinical trials with younger patients, in which the elderly have been often neglected and underrepresented[3].

Since the publication of the CROSS study[4], neoadjuvant chemoradiotherapy (CRT) followed by esophagectomy is recommended for patients with potentially curable EC, according to the National Comprehensive Cancer Network and other guidelines[5]. However, elderly patients tend to have poorer performance scores, more multiple comorbidities, and shorter life expectancy compared to young individuals. Moreover, they might be less tolerant to esophagectomy or definitive CRT due to severe complications and side effects[6-8]. Thus, treatment for elderly patients with esophageal carcinoma appears to be underutilized[9]. Controversies on the selection of the optimal treatment strategy for elderly patients with curable EC, including esophagectomy versus CRT $[10,11]$ or CRT versus radiotherapy (RT) alone, still exist $[8,12]$. For instance, Abrams JA et al. have reported that esophagectomy may be associated with better survival for early-stage EC patients aged $\geq 65$ years compared to CRT[11], whereas Koeter $\mathrm{M}$ et al. have found that survival was comparable among elderly patients (aged $\geq 75$ years) with esophageal squamous cell carcinoma (ESCC) who underwent surgery or received definitive CRT.[10] However, most previous studies have included a small number of samples or only compared the efficiency of two main treatment patterns[10,11], with inconsistent definitions of "elderly population" from aged 65 years and older[11, 13] to $\geq$ $70[12,14]$ or 75 years[10] or more than 80 years[15]. Given the conflicting and insufficient data on this patient population, the optimal treatment strategy for elderly patients with potentially curable EC needs to be further investigated. 
In the present study, we systematically evaluated all treatment patterns and outcomes of elderly patients with potentially curable EC using the Surveillance, Epidemiology, and End Results (SEER) database. To provide a comprehensive understanding of the impact of age on treatment selection and survival outcome, patients were further divided into four age groups, age $70-74,75-79,80-84$, and $\geq 85$ years.

\section{Methods}

\section{Patient Selection}

\section{Data Source}

This study involved extraction of eligible patient-level data on elderly EC cases from the SEER database, which collects data on cancer incidence, treatment, and survival from population-based cancer registries, covering $26 \%$ of the US population[16]. In our study, elderly patients were referred to those aged 70 years or older, mainly according to the definitions of elderly patients with NSCLC $[17,18]$. To reflect the modern radiation technology (intensity-modulated RT) and recent advancement in EC treatment, patients aged $\geq 70$ years with potentially curable EC diagnosed from 2010 to 2016 were identified from the SEER database using SEER*Stat software (version 8.3.8, NIH, USA).

\section{Inclusion Criteria}

The inclusion criteria were as follows: (1) patients with histologically confirmed EC, esophageal adenocarcinoma (EAC), or ESCC; (2) patients aged > 70 years; (3) patients with stage T1b-T4aNxM0, according to the guidelines of the American Joint Committee on Cancer 7th edition; (4) patients with treatment information, including surgery, radiation sequence with surgery, and chemotherapy (CT).

\section{Exclusion Criteria}

The exclusion criteria were as follows: (1) patients with stage T0-1a, 4b, X, or M1 or nonspecific stage; (2) patients with other histological subtypes such as neuroendocrine carcinoma, signet ring cell carcinoma, mucinous adenocarcinoma, and other malignant neoplasms; (3) patients who underwent endoscopic resection; (4) patients receiving resection through biopsy or regional lymph node aspiration; and (5) patients with missing or incomplete data on treatment information including RT or survival status.

\section{Study Definitions}

In our study, treatment patterns for elderly patients were divided into five groups: surgical resection (S), CRT, RT, CT, or observation with no treatment (Obs). The treatment definitions were as follows: the treatment of surgery was defined as patients who underwent esophagectomy alone or combined with RT or CT, whereas CRT referred to patients receiving RT with $\mathrm{CT}$, concurrent or sequential. RT or CT was defined as patients receiving RT or CT alone. The primary endpoint in our study was overall survival (OS), and the secondary endpoint was cancer-specific survival (CSS), which was defined as the intervals between the date of diagnosis and the occurrence of any-cause or cancer-specific death, respectively.

\section{Statistical Analyses}

Differences in baseline characteristics between patients treated with different patterns were compared using Pearson's chisquared test. Multinomial logistic regression was used to determine the predictors of the use of surgery-based treatment. Survival was estimated using the Kaplan-Meier method, and the log-rank test was used to compare survival curves. Univariate Cox regression analysis was performed to identify the significant variables associated with survival, and variables with a $\mathrm{p}$ value less than 0.10 were included in the multivariate Cox model. $\mathrm{P}$ for the interaction between subgroup analyses was calculated using the likelihood ratio test. All tests were two-sided, and $p$ values $<0.05$ were considered statistically significant. Statistical analysis was performed using R version 3.4.1 and the International Business Machines (IBM) Statistical Package for the Social Sciences statistics software (version 22.0; IBM Corp., Armonk, NY, USA). 


\section{Results}

\section{Patient Characteristics and Patterns of Care}

From 2010 to 2016, a total of 24006 newly diagnosed patients with EC were found in the SEER database; $43.55 \%$ ( $N=$ 10455 ) of them were elderly patients aged $>70$ years. According to the inclusion criteria, 3233 patients with potentially curable EC were identified in our study. Of all the patients included, $29.1 \%(n=941)$ received surgery, $48.2 \%(N=1559)$ received CRT, 8.7\% $(N=281)$ received $R T$, and 3.5\% $(N=113)$ received $C T$, whereas $10.5 \%(N=339)$ underwent Obs. $A$ flowchart of patient selection was presented in Fig. 1. Data were broadly collected for each patient for analysis, including patient characteristics, clinicopathologic tumor parameters, treatment, and survival information. Baseline patient demographics and clinical and tumor characteristics are listed in Table 1. As shown in Fig. 2, patients receiving surgery tended to be younger, with an increase in age, and an increasing number of patients underwent RT alone or Obs. Other variables significantly associated with receiving surgery included earlier T stage (odds ratio [OR] for T1a $=21.17,95 \%$ confidence interval [Cl]: 11.22-39.96, p<0.001; OR for T2 =6.27, 95\% Cl: 3.62-10.85; OR for T3 = 6.28, 95\% Cl: 3.80-10.37), marital status $(\mathrm{OR}=1.89,95 \% \mathrm{Cl}: 1.05-3.40, \mathrm{p}=0.033)$, middle or lower third location of primary lesions (OR for middle location $=3.00,95 \% \mathrm{Cl}: 1.70-5.30, \mathrm{p}<0.001 ;$ OR for lower location $=3.58,95 \% \mathrm{Cl}: 2.24-5.71, \mathrm{p}<0.001)$. 
Table 1

Baseline Patient Demographics and Clinical and Tumor Characteristics

\begin{tabular}{|c|c|c|c|c|c|c|c|}
\hline Variables & $\begin{array}{l}\text { Total } \\
\begin{array}{l}N=3233 \\
(100 \%)\end{array}\end{array}$ & $\begin{array}{l}S \\
N= \\
941(29.1 \%)\end{array}$ & $\begin{array}{l}\text { CRT } \\
N= \\
1559(48.2 \%)\end{array}$ & $\begin{array}{l}\text { RT } \\
N= \\
281(8.7 \%)\end{array}$ & $\begin{array}{l}\text { CT } \\
N= \\
113(3.5 \%)\end{array}$ & $\begin{array}{l}\text { Obs } \\
\begin{array}{l}N= \\
339(10.5 \%)\end{array}\end{array}$ & $\begin{array}{l}P \\
\text { value }\end{array}$ \\
\hline $\begin{array}{l}\text { Age at diagnosis } \\
70-74 \text { years } \\
75-79 \text { years } \\
80-84 \text { years } \\
85+\text { years }\end{array}$ & $\begin{array}{l}1199 \\
(37.1 \%) \\
938(29.0 \%) \\
662(20.5 \%) \\
434(13.4 \%)\end{array}$ & $\begin{array}{l}465 \\
(49.4 \%) \\
300(31.9 \%) \\
138(14.7) \\
38(4.0 \%)\end{array}$ & $\begin{array}{l}555(35.6 \%) \\
475(30.5 \%) \\
341(21.9 \%) \\
188(12.0 \%)\end{array}$ & $\begin{array}{l}45(16.0 \%) \\
56(19.9 \%) \\
83(29.5 \%) \\
97(37.7 \%)\end{array}$ & $\begin{array}{l}51(45.1 \%) \\
36(31.9 \%) \\
16(14.2 \%) \\
10(8.8 \%)\end{array}$ & $\begin{array}{l}83(24.5 \%) \\
71(20.9 \%) \\
84(24.8 \%) \\
101(29.8 \%)\end{array}$ & $\begin{array}{l}< \\
0.001\end{array}$ \\
\hline $\begin{array}{l}\text { Sex } \\
\text { Male } \\
\text { Female }\end{array}$ & $\begin{array}{l}2423(74.9 \%) \\
810(25.1 \%)\end{array}$ & $\begin{array}{l}762(81.0 \%) \\
179(19.0 \%)\end{array}$ & $\begin{array}{l}1152(73.9 \%) \\
407(26.1 \%)\end{array}$ & $\begin{array}{l}200(71.2 \%) \\
81(28.8 \%)\end{array}$ & $\begin{array}{l}85(75.2 \%) \\
28(24.8 \%)\end{array}$ & $\begin{array}{l}224(66.1 \%) \\
115(33.9 \%)\end{array}$ & $\begin{array}{l}< \\
0.001\end{array}$ \\
\hline $\begin{array}{l}\text { Race } \\
\text { White } \\
\text { Black } \\
\text { Others }\end{array}$ & $\begin{array}{l}2884(89.2 \%) \\
191(5.9 \%) \\
158(4.9 \%)\end{array}$ & $\begin{array}{l}879(93.4 \%) \\
30(3.2 \%) \\
32(3.4 \%)\end{array}$ & $\begin{array}{l}1379(88.5 \%) \\
105(6.7 \%) \\
75(4.8 \%)\end{array}$ & $\begin{array}{l}239(85.0 \%) \\
21(7.5 \%) \\
21(7.5 \%)\end{array}$ & $\begin{array}{l}96(85.0 \%) \\
8(7.0 \%) \\
9(8.0 \%)\end{array}$ & $\begin{array}{l}291(85.8 \%) \\
27(8.0 \%) \\
21(6.2 \%)\end{array}$ & $\begin{array}{l}<.001 \\
0.00\end{array}$ \\
\hline $\begin{array}{l}\text { Histological subtype } \\
\text { Adenocarcinoma } \\
\text { Squamous cell }\end{array}$ & $\begin{array}{l}1182 \\
(36.6 \%) \\
2051 \\
(63.4 \%)\end{array}$ & $\begin{array}{l}203(21.6 \%) \\
738(78.4 \%)\end{array}$ & $\begin{array}{l}679(43.6 \%) \\
880(56.4 \%)\end{array}$ & $\begin{array}{l}134(47.7 \%) \\
147(52.3 \%)\end{array}$ & $\begin{array}{l}40(35.4 \%) \\
73(64.6 \%)\end{array}$ & $\begin{array}{l}126(37.2 \%) \\
213(62.8 \%)\end{array}$ & $\begin{array}{l}<.001 \\
0.00\end{array}$ \\
\hline $\begin{array}{l}\text { Stage } \\
\text { I } \\
\text { II } \\
\text { III }\end{array}$ & $\begin{array}{l}250(7.7 \%) \\
1459(45.2 \%) \\
1524(47.1 \%)\end{array}$ & $\begin{array}{l}189(20.1 \%) \\
344(36.5 \%) \\
408(43.4 \%)\end{array}$ & $\begin{array}{l}32(2.1 \%) \\
751(48.2 \%) \\
776(49.7 \%)\end{array}$ & $\begin{array}{l}6(2.1 \%) \\
165(58.7 \%) \\
110(39.2 \%)\end{array}$ & $\begin{array}{l}2(1.8 \%) \\
44(38.9 \%) \\
67(59.3 \%)\end{array}$ & $\begin{array}{l}21(6.2 \%) \\
155(45.7 \%) \\
163(48.1 \%)\end{array}$ & $\begin{array}{l}< \\
0.001\end{array}$ \\
\hline $\begin{array}{l}\text { T stage } \\
\mathrm{T} 1 \mathrm{~b}\end{array}$ & $326(9.8 \%)$ & $223(23.7 \%)$ & $49(3.1 \%)$ & $8(2.8 \%)$ & $7(6.2 \%)$ & $29(8.6 \%)$ & $\begin{array}{l}<.001 \\
0.00\end{array}$ \\
\hline $\begin{array}{l}\text { T2 } \\
\text { T3 } \\
\text { T4a }\end{array}$ & $\begin{array}{l}740(22.9 \%) \\
1959(60.6 \%) \\
218(6.7 \%)\end{array}$ & $\begin{array}{l}181(19.2 \%) \\
507(53.9 \%) \\
30(3.2 \%)\end{array}$ & $\begin{array}{l}394(25.3 \%) \\
1030(66.1 \%) \\
86(5.5 \%)\end{array}$ & $\begin{array}{l}69(24.6 \%) \\
185(65.8 \%) \\
19(6.8 \%)\end{array}$ & $\begin{array}{l}22(19.5 \%) \\
71(62.8 \%) \\
13(11.5 \%)\end{array}$ & $\begin{array}{l}74(21.8 \%) \\
166(49.0 \%) \\
70(20.6 \%)\end{array}$ & \\
\hline $\begin{array}{l}\text { N stage } \\
\text { NO }\end{array}$ & $1509(46.7 \%)$ & $457(48.6 \%)$ & $656(42.1 \%)$ & $163(58.4 \%)$ & $41(36.3 \%)$ & 191(56.3\%) & $\begin{array}{l}< \\
0.001\end{array}$ \\
\hline N1 & $1340(41.4 \%)$ & $353(37.5 \%)$ & $711(45.6 \%)$ & $91(32.4 \%)$ & $58(51.3 \%)$ & 127(37.5\%) & \\
\hline N2 & $321(9.9 \%)$ & $105(11.2 \%)$ & $168(10.8 \%)$ & $22(7.8 \%)$ & 11(9.7\%) & $15(4.4 \%)$ & \\
\hline N3 & $63(1.9 \%)$ & $26(2.8 \%)$ & $24(1.5 \%)$ & $4(1.4 \%)$ & $3(2.7 \%)$ & $6(1.8 \%)$ & \\
\hline
\end{tabular}




\begin{tabular}{|c|c|c|c|c|c|c|c|}
\hline \multirow[t]{2}{*}{ Variables } & Total & S & CRT & RT & CT & Obs & \multirow{2}{*}{$\begin{array}{l}P \\
\text { value }\end{array}$} \\
\hline & $\begin{array}{l}N=3233 \\
(100 \%)\end{array}$ & $\begin{array}{l}\mathrm{N}= \\
941(29.1 \%)\end{array}$ & $\begin{array}{l}\mathrm{N}= \\
1559(48.2 \%)\end{array}$ & $\begin{array}{l}\mathrm{N}= \\
281(8.7 \%)\end{array}$ & $\begin{array}{l}\mathrm{N}= \\
113(3.5 \%)\end{array}$ & $\begin{array}{l}\mathrm{N}= \\
339(10.5 \%)\end{array}$ & \\
\hline \multicolumn{7}{|l|}{ Grade } & \multirow{6}{*}{$<_{0.001}^{<}$} \\
\hline Well (G1) & $206(6.4 \%)$ & $66(7.0 \%)$ & $88(5.6 \%)$ & $19(6.8 \%)$ & $5(4.4 \%)$ & $28(8.3 \%)$ & \\
\hline Moderate (G2) & $1240(38.4 \%)$ & $403(42.8 \%)$ & $593(38.0 \%)$ & $98(34.9 \%)$ & $38(33.6 \%)$ & $108(31.9 \%)$ & \\
\hline Poorly (G3) & $1212(37.5 \%)$ & $379(40.3 \%)$ & $561(36.0 \%)$ & $111(39.5 \%)$ & $48(42.5 \%)$ & $113(33.3 \%)$ & \\
\hline Undifferentiated(G4) & $34(1.1 \%)$ & $12(1.3 \%)$ & $14(0.9 \%)$ & $1(0.0 \%)$ & $1(0.9 \%)$ & $6(1.8 \%)$ & \\
\hline Unknown & $541(16.7 \%)$ & $81(8.6 \%)$ & $303(19.4 \%)$ & $52(18.5 \%)$ & $21(18.6 \%)$ & $84(24.8 \%)$ & \\
\hline \multicolumn{7}{|l|}{ Tumor location } & \multirow{5}{*}{$\begin{array}{c}< \\
0.001\end{array}$} \\
\hline Upper third & $260(8.0 \%)$ & $28(3.0 \%)$ & $162(10.4 \%)$ & $29(10.3 \%)$ & $8(7.1 \%)$ & $33(9.7 \%)$ & \\
\hline Middle third & $660(20.4 \%)$ & $127(13.5 \%)$ & $376(24.1 \%)$ & $81(28.8 \%)$ & 19(16.8\%) & $57(16.8 \%)$ & \\
\hline Lower third & $2055(63.6 \%)$ & 733(77.9\%) & $901(57.8 \%)$ & $154(54.8 \%)$ & $66(58.4 \%)$ & $201(59.3 \%)$ & \\
\hline Unknown & $258(8.0 \%)$ & $53(5.6 \%)$ & $120(7.7 \%)$ & $17(6.1 \%)$ & $20(17.7 \%)$ & $48(14.2 \%)$ & \\
\hline \multicolumn{7}{|l|}{ Marital status } & \multirow{4}{*}{$\iota_{0.001}^{<}$} \\
\hline Married & $1876(58.0 \%)$ & $613(65.1 \%)$ & $915(58.7 \%)$ & $141(50.2 \%)$ & 70(61.9\%) & 137(40.4\%) & \\
\hline Unmarried & 1193(36.9\%) & $284(30.2 \%)$ & $574(36.8 \%)$ & $126(44.8 \%)$ & $29(25.7 \%)$ & $180(53.1 \%)$ & \\
\hline Unknown & $164(5.1 \%)$ & $44(4.7 \%)$ & $70(4.5 \%)$ & $14(8.5 \%)$ & $14(12.4 \%)$ & $22(6.5 \%)$ & \\
\hline
\end{tabular}

\section{Survival Analyses}

In the overall analysis for OS, patients receiving surgery showed significantly better survival than patients who underwent other treatment patterns, whereas observation resulted in the worst survival, as shown in Fig. 3A. The 3-year OS estimates were 45.80\% (95\% Cl: 42.20-49.80\%), 26.10\% (95\% Cl: 23.50-28.90\%), 12.21\% (95\% Cl: 8.37-17.80\%), 14.87\% (8.38$26.39 \%)$, and $6.66 \%$ (95\% Cl: 4.04-11.00\%) for S, CRT, RT, CT, and Obs ( $<<0.001)$, respectively. Compared to Obs, any treatment pattern was associated with superior OS, and the hazard ratios for S, CRT, RT, and CT were 0.19 (95\% Cl: $0.16-$ 0.22), 0.32 (95\% Cl: 0.28-0.36), 0.58 (95\% Cl: 0.49-0.69), and 0.49 (95\% Cl: 0.38-0.63) ( $<<0.001)$, respectively. Further pairwise comparisons between groups showed that surgery significantly resulted in better outcomes compared to any other treatment patterns $(p<0.01)$, and patients receiving CRT had a significant survival advantage over RT or CT alone $(p<0.01)$. Moreover, no significant survival differences were observed between patients who underwent RT or CT $(p=0.18)$. For CSS, similar results were found (Fig. 3B), and the 3-year CSS estimates were $66.50 \%$ (95\% Cl: 62.50-46.50\%), 46.30\% (95\% Cl: 42.23-42.00\%), 30.22\% (95\% Cl: 22.83-40.14\%), 29.36\% (95\% Cl: 17.92-48.09\%), and $21.60 \%$ (95\% Cl: $14.94-31.32 \%)$ for $\mathrm{S}, \mathrm{CRT}, \mathrm{RT}, \mathrm{CT}$, and Obs $(\mathrm{p}<0.001)$, respectively, indicating the reliability of the results.

When further stratified by age group, as shown in Fig. 4, the superiority of surgery was observed in all four age groups. However, the survival benefits of surgery over CRT gradually weakened with the increase in age, and the 3 year-OS estimates were $31.54 \%$ (95\% Cl: $18.22-54.51 \%)$ for S and $25.52 \%$ (95\% Cl: $18.54-35.03 \%)$ for CRT in EC patients aged > 80 years, and the survival benefit of surgery was statistically nonsignificant $(p=0.41)$. Subgroup analyses stratified by other factors, including race, pathology, grade, stage, location, and marital status, also supported the superiority of surgery, and the results are presented in Table S1. 


\section{Predictive factors for overall survival in elderly patients with esophageal cancer}

Univariate Cox regression analysis was performed to identify the variables associated with OS in the selected cohort, and the significant predictive factors included age, grade, T stage, N stage, marital status, and treatment patterns. Race, sex, pathological subtype, and tumor location were not significantly associated with OS on univariate analysis. The results are presented in Table 2. On multivariate Cox regression analysis, treatment pattern was still a statistically significant factor for improved OS ( $\mathrm{p}$ 0.001). Other significant factors identified by multivariate analysis included age, tumor grade, T stage, $\mathrm{N}$ stage, and marital status $(p<0.05)$. Based on these predictive factors found on multivariate analysis, predictive nomograms based on Fine and Gray's model were constructed to predict the 3- and 5-year cumulative incidence of OS for elderly patients with operable EC (Fig. 5), and the concordance index for the prediction of OS was calculated (0.68, 95\% Cl:0.66-0.70). In addition, the areas under the curve of the receiver operating characteristic curves for 3-year and 5-year OS were 0.72 and 0.74, respectively (Fig. 6A-B). The calibration plots for the 3-year and 5-year cumulative probabilities of OS are presented in Fig. 6C-D, which showed good consistency between nomogram prediction and actual observation. 
Table 2

Univariate Analysis and Multivariate Cox regression analysis of OS in in elderly EC patients with $\geq 70$ years

\begin{tabular}{|c|c|c|c|c|}
\hline \multirow[b]{2}{*}{ Variables } & \multicolumn{2}{|c|}{ Univariate Analysis } & \multicolumn{2}{|c|}{ Multivariate analysis } \\
\hline & HR with $95 \% \mathrm{Cl}$ & $p$ value & HR with $95 \% \mathrm{Cl}$ & $p$ value \\
\hline \multicolumn{5}{|l|}{ Age } \\
\hline $70-74$ years & 1 & $<0.001$ & 1 & 0.187 \\
\hline $75-79$ years & $1.11(0.99-1.24)$ & $<0.001$ & $1.08(0.96-1.21)$ & 0.129 \\
\hline $80-84$ years & $1.28(1.13-1.15)$ & $<0.001$ & $1.10(0.97-1.25)$ & $<0.001$ \\
\hline $85+$ years & $1.88(1.65-2.16)$ & & $1.35(1.17-1.56)$ & \\
\hline \multicolumn{5}{|l|}{ Sex } \\
\hline Male & 1 & 0.13 & & \\
\hline Female & $0.92(0.83-1.02)$ & & & \\
\hline \multicolumn{5}{|l|}{ Race } \\
\hline White & 1 & & & \\
\hline Black & $1.14(0.95-1.36)$ & 0.16 & & \\
\hline Others & $1.01(0.82-1.25)$ & 0.92 & & \\
\hline Pathology & 1 & 0.37 & & \\
\hline Adenocarcinoma & $0.96(0.88-1.05)$ & & & \\
\hline \multicolumn{5}{|l|}{ Squamous cell } \\
\hline \multicolumn{5}{|l|}{ Grade } \\
\hline Well (G1) & 1 & 0.086 & 1 & 0.012 \\
\hline Moderate (G2) & $1.19(0.97-1.46)$ & $<0.001$ & $1.30(1.06-1.59)$ & $<0.001$ \\
\hline Poorly (G3) & $1.46(1.20-1.79)$ & $<0.001$ & $1.48(1.21-1.81)$ & 0.076 \\
\hline Undifferentiated(G4) & $1.40(0.87-2.26)$ & 0.017 & $1.55(0.96-2.52)$ & 0.31 \\
\hline Unknown & $1.31(1.05-1.63)$ & & $1.12(0.90-0.40)$ & \\
\hline \multicolumn{5}{|l|}{ Stage } \\
\hline I & 1 & $<0.001$ & 1 & 0.69 \\
\hline ॥ & $1.90(1.55-2.34)$ & $<0.001$ & $0.92(0.59-1.41)$ & 0.92 \\
\hline III & $2.46(2.01-3.02)$ & & $1.02(0.61-1.74)$ & \\
\hline \multicolumn{5}{|l|}{ T stage } \\
\hline $\mathrm{T} 1 \mathrm{~b}$ & 1 & $<0.001$ & 1 & 0.088 \\
\hline T2 & $1.63(1.33-1.98)$ & $<0.001$ & $1.39(0.95-2.04)$ & 0.003 \\
\hline T3 & $2.23(1.86-2.67)$ & $<0.001$ & $1.80(1.22-2.67)$ & $<0.001$ \\
\hline $\mathrm{T} 4 \mathrm{a}$ & $3.54(2.81-4.45)$ & & $2.31(1.45-3.67)$ & \\
\hline
\end{tabular}




\begin{tabular}{|c|c|c|c|c|}
\hline & \multicolumn{2}{|c|}{ Univariate Analysis } & \multicolumn{2}{|c|}{ Multivariate analysis } \\
\hline No & 1 & 0.031 & 1 & 0.56 \\
\hline N1 & $1.11(1.01-1.22)$ & 0.003 & $0.95(0.80-1.13)$ & 0.36 \\
\hline N2 & $1.26(1.08-1.47)$ & $<0.001$ & $1.12(0.88-1.41)$ & 0.001 \\
\hline N3 & $1.98(1.47-2.67)$ & & $1.81(1.29-2.56)$ & \\
\hline \multicolumn{5}{|c|}{ Tumor location } \\
\hline Upper third & 1 & 0.39 & & \\
\hline Middle third & $0.92(0.77-1.11)$ & 0.31 & & \\
\hline Lower third & $0.92(0.78-1.08)$ & 0.97 & & \\
\hline Unknown & $1.01(0.81-1.25)$ & & & \\
\hline \multicolumn{5}{|c|}{ Treatment patterns } \\
\hline Obs & 1 & $<0.001$ & 1 & $<0.001$ \\
\hline Surgery & $0.19(0.16-0.22)$ & $<0.001$ & $0.20(0.17-0.24)$ & $<0.001$ \\
\hline CRT & $0.32(0.28-0.36)$ & $<0.001$ & $0.31(0.27-0.36)$ & $<0.001$ \\
\hline RT & $0.58(0.49-0.69)$ & $<0.001$ & $0.54(0.45-0.64)$ & $<0.001$ \\
\hline $\mathrm{CT}$ & $0.49(0.38-0.63)$ & & $0.48(0.37-0.62)$ & \\
\hline \multicolumn{5}{|c|}{ Marital status } \\
\hline Married & 1 & $<0.001$ & 1 & 0.17 \\
\hline Unmarried & $1.23(1.12-1.35)$ & 0.50 & $1.07(0.97-1.18)$ & 0.48 \\
\hline Unknown & $1.07(0.87-1.32)$ & & $0.93(0.75-1.14)$ & \\
\hline
\end{tabular}

\section{Discussion}

In this large, population-based study, patterns of treatment and outcomes of elderly patients with potentially curable EC were comprehensively analyzed. The results showed that the usage ratios of surgery were reduced with the increase in age, CRT was mostly adapted in patients with locally advanced-stage EC, and RT alone was also employed, especially in patients aged $\geq 80$ years. The survival analysis indicated that all the treatment patterns had survival benefits in elderly patients compared to Obs. The use of surgery was associated with improved OS in all older age groups, and CRT was superior to RT or CT alone. The results were stable across subgroup analyses stratified by most factors, including sex, clinical stage, histological subtype, and tumor location, demonstrating the reliability of our conclusions.

In younger patients, surgery-based trimodality therapy has been the standard treatment for locally advanced EC[19, 20]. However, elderly patients tend to have a decline in physiological function and a high prevalence of chronic diseases, such as high blood pressure, diabetes, and cardiovascular system diseases, which make them difficult to respond to surgical trauma and recover slowly[21]. Elderly patients undergoing esophagectomy for cancer are reported to have a significantly higher risk of postoperative mortality, especially in patients aged 75 years or older[22-24]. Hence, elderly patients with EC should be 
cautiously evaluated and selected for surgery[25]. In fact, only one-third of patients in our cohort underwent surgical resection, and the number of patients who underwent surgery decreased dramatically with increasing age. In this study, a significantly small number of patients $(<10 \%)$ aged $>80$ years underwent surgery, reflecting concerns about postoperative morbidity and the underuse of surgery in elderly patients with EC.

In the survival analysis, elderly patients who underwent surgery lived significantly longer than those who received other treatment patterns, including CRT. The advantage of surgery was stable in both EAC and ESCC and across stages I to III. At the same time, other retrospective studies have supported the use of surgery in elderly patients with EC, and esophagectomy was found to be associated with improved survival, even with increased risk of complications in elderly patients with EC[6, $10,11,26,27]$. In fact, it is reported that trimodality therapy is also an acceptable treatment option for properly selected elderly patients with EC[28]. In addition to these findings, our study showed that the survival benefit of surgery can be observed even in patients aged $>80$ years, whereas the benefit was comparable with that of CRT among elderly patients aged 85 years and over. Therefore, after comprehensive assessment and rigid screening, surgical treatment with or without neoadjuvant treatment should be preferentially recommended for elderly patients with good performance status and long expected life span, as the same treatment pattern for young patients, given the improved outcomes with treatment. For patients intolerable to surgery or aged $>80$ years, radical RT can be considered as an alternative option.

Considering postoperative morbidity and reduced quality of life, a large proportion of patients with EC favor non-operative treatment patterns. In our analysis, almost half of the patients selected CRT as their primary treatment, and $22 \%$ of patients aged 85 years and over received RT alone. In the survival analysis, the survival benefit of CRT was only next to surgery and superior to RT or CT alone. CRT has been the standard therapy for patients with locally advanced EC ineligible for surgery since the Radiation Therapy Oncology Group 85 - 01 trial, and no patients survived for 5 years in the RT alone group[29]. However, in clinical practice, due to concerns regarding treatment-related adverse effects, including esophagitis, pneumonitis, and hematologic toxicity, several elderly EC patients only undergo RT alone[30, 31]. Several previous studies have demonstrated that CRT might be considered as both effective and safe in elderly patients with EC, exhibiting similar long-term clinical benefits compared to younger patients[32-34]. Our study confirmed the superiority of CRT over RT alone among all elderly age groups in a large population. RT alone should be recommended with caution even in the eldest group (aged > 85 years). If patients cannot tolerate doublet CT combined with RT, single-drug oral CT drugs can be considered, such as S1, Xeloda, and other fluorouracil analogues[12, 35].

Our study has the following strengths. First, our study used a population-based database with a large sample size and longterm follow-up period. Second, a comprehensive analysis of primary treatment patterns and wide-ranging subgroup analysis stratified by age, which made the conclusion reliable and stable, were performed in our study. However, our study has several limitations. First, as with any retrospective study, selection bias and unmeasured confounding variables are inevitable, and the baseline characteristics of patients in different patterns were not well balanced, which reflected real-world treatment choices. Second, some information was missing on patient characteristics and treatment processes in the SEER database, such as performance status, CT regimens, and comorbidities, which limited the multivariate Cox regression analysis. Additionally, for study endpoints, data regarding recurrence and metastasis information were unavailable.

Given the natural limitations of retrospective studies, the findings of our study should be interpreted with caution in clinical practice. As described in the limitations of our study, selection bias should be considered. When selecing the optimal treatment pattern for elderly patients with EC, their physical conditions should be comprehensively assessed, including nutritional status, cardiopulmonary function, and associated underlying diseases. If possible, a comprehensive geriatric assessment (CGA) is recommended, which has been increasingly involved in guiding treatment decisions for elderly cancer patients[19]. In younger patients with high CGA scores, more aggressive treatment options, such as surgery combined with neoadjuvant CRT, may be considered as the first option. For patients with higher age (aged $\geq 85$ years) or poor general condition or unsuitable for surgery (regardless of medical reasons), CRT was the preferred treatment pattern. For patients 
with poor health, palliative RT for local tumors combined with supportive nutrition treatment might extend the survival of patients and improve their quality of life[36].

\section{Conclusion}

In this large sample population-based study, we found that curative-intent treatment patterns can provide survival benefits for elderly patients with EC. Surgical resection is associated with longest survival and thus should be considered as the first option, if it is feasible. Subsequently, CRT is remarkably superior to RT or CT alone in elderly patients with EC. For patients intolerable to surgery or aged $\geq 80$ years, definitive CRT should be considered as a preferable option. Age is not a restrictive condition for treatment options in elderly EC patients, and the optimal treatment strategy should take into account CGA with survival benefits and patient preferences in a multidisciplinary setting. Future clinical trials are needed to validate our findings and to reduce the occurrence of complications in the elderly population.

\section{Abbreviations}

EC: esophageal cancer; SEER: the Surveillance, Epidemiology and End Results database; EAC: esophageal adenocarcinoma; ESCC: esophageal squamous cell carcinoma; S: surgical resection; CRT: chemoradiotherapy; RT: radiotherapy; CT: chemotherapy; Obs: observation with no treatment; OS: overall survival; CSS: cancer-specific survival; AUC: area under the curve; ROC: receiver operating characteristic curve; CGA : comprehensive geriatric assessment

\section{Declarations}

\section{Ethics approval and consent to participate}

As all the data of this study were derived from the SEER database, ethics approval and consent to participate were not required

\section{Consent for publication}

Not applicable.

\section{Availability of data and materials}

The data were collected from the Surveillance, Epidemiology, and End Results (SEER) database (URL: https://seer.cancer.gov/, Accession username: 20291-Nov2018).

\section{Competing interests}

The authors have no conflicts of interest to declare.

\section{Funding}

This work was supported by the fund of National Natural Science Foundation of China (No. 81702968) and Zhejiang Province Medical and Health Science and Technology Project (2016RCB002).

\section{Authors' contributions}

Wei Q and Yang Y conceived and drafted the study; Yang Y and Chen M collected and extracted the data, Yang Y, Chen M and Xie $\mathrm{J}$ designed the statistical analysis plan and performed the analyses. Yang Y, Ji Y and Sheng L interpreted the results and prepared the manuscript. Qiu G and Du X carefully revised the manuscript. All authors commented on drafts of the paper and approved the final manuscript. 


\section{Acknowledgments}

Not applicable.

\section{References}

1. Sung H, Ferlay J, Siegel RL et al. Global cancer statistics 2020: GLOBOCAN estimates of incidence and mortality worldwide for 36 cancers in 185 countries. CA Cancer J Clin 2021; 0: 1-41.

2. Collaborators GBDOC. The global, regional, and national burden of oesophageal cancer and its attributable risk factors in 195 countries and territories, 1990-2017: a systematic analysis for the Global Burden of Disease Study 2017. Lancet Gastroenterol Hepatol 2020; 5: 582-597.

3. Bollschweiler E, Plum P, Monig SP, Holscher AH. Current and future treatment options for esophageal cancer in the elderly. Expert Opin Pharmacother 2017; 18: 1001-1010.

4. van Hagen P, Hulshof MC, van Lanschot JJ et al. Preoperative chemoradiotherapy for esophageal or junctional cancer. N Engl J Med 2012; 366: 2074-2084.

5. Ajani JA, D'Amico TA, Bentrem DJ et al. Esophageal and Esophagogastric Junction Cancers, Version 2.2019, NCCN Clinical Practice Guidelines in Oncology. J Natl Compr Canc Netw 2019; 17: 855-883.

6. Farrow NE, Raman V, Jawitz OK et al. Impact of Age on Surgical Outcomes for Locally Advanced Esophageal Cancer. Ann Thorac Surg 2020.

7. Markar SR, Karthikesalingam A, Thrumurthy S et al. Systematic review and pooled analysis assessing the association between elderly age and outcome following surgical resection of esophageal malignancy. Diseases of the Esophagus 2013; 26: 250-262.

8. Wakui R, Yamashita H, Okuma K et al. Esophageal cancer: definitive chemoradiotherapy for elderly patients. Dis Esophagus 2010; 23: 572-579.

9. Molena D, Stem M, Blackford A, Lidor A. Esophageal Cancer Treatment Is Underutilized Among Elderly Patients in the USA. Journal of gastrointestinal surgery: official journal of the Society for Surgery of the Alimentary Tract 2017; 21: $126-136$.

10. Koeter M, van Putten M, Verhoeven RHA et al. Definitive chemoradiation or surgery in elderly patients with potentially curable esophageal cancer in the Netherlands: a nationwide population-based study on patterns of care and survival. Acta Oncol 2018; 57: 1192-1200.

11. Abrams JA, Buono DL, Strauss J et al. Esophagectomy compared with chemoradiation for early stage esophageal cancer in the elderly. Cancer 2009; 115: 4924-4933.

12. Wang X, Ge X, Wang X et al. S-1-Based Chemoradiotherapy Followed by Consolidation Chemotherapy With S-1 in Elderly Patients With Esophageal Squamous Cell Carcinoma: A Multicenter Phase II Trial. Front Oncol 2020; 10: 1499.

13. Smith GL, Smith BD, Buchholz TA et al. Patterns of care and locoregional treatment outcomes in older esophageal cancer patients: The SEER-Medicare Cohort. Int J Radiat Oncol Biol Phys 2009; 74: 482-489.

14. Luo H, Jiang W, Ma L et al. Icotinib With Concurrent Radiotherapy vs Radiotherapy Alone in Older Adults With Unresectable Esophageal Squamous Cell Carcinoma: A Phase II Randomized Clinical Trial. JAMA Netw Open 2020; 3 : e2019440.

15. Moreno AC, Verma V, Hofstetter WL, Lin SH. Patterns of Care and Treatment Outcomes of Elderly Patients with Stage I Esophageal Cancer: Analysis of the National Cancer Data Base. J Thorac Oncol 2017; 12: 1152-1160.

16. Yu JB, Gross CP, Wilson LD, Smith BD. NCI SEER public-use data: applications and limitations in oncology research. Oncology (Williston Park) 2009; 23: 288-295.

17. Quoix E, Zalcman G, Oster JP et al. Carboplatin and weekly paclitaxel doublet chemotherapy compared with monotherapy in elderly patients with advanced non-small-cell lung cancer: IFCT-0501 randomised, phase 3 trial. Lancet 
2011; 378: 1079-1088.

18. Miller ED, Fisher JL, Haglund KE et al. The Addition of Chemotherapy to Radiation Therapy Improves Survival in Elderly Patients with Stage III Non-Small Cell Lung Cancer. J Thorac Oncol 2018; 13: 426-435.

19. Cohen HJ, Feussner JR, Weinberger $\mathrm{M}$ et al. A controlled trial of inpatient and outpatient geriatric evaluation and management. N Engl J Med 2002; 346: 905-912.

20. Yang H, Liu H, Chen $\mathrm{Y}$ et al. Neoadjuvant Chemoradiotherapy Followed by Surgery Versus Surgery Alone for Locally Advanced Squamous Cell Carcinoma of the Esophagus (NEOCRTEC5010): A Phase III Multicenter, Randomized, OpenLabel Clinical Trial. J Clin Oncol 2018; 36: 2796-2803.

21. Harridge SD, Lazarus NR. Physical Activity, Aging, and Physiological Function. Physiology (Bethesda) 2017; 32: 152161.

22. Tapias LF, Muniappan A, Wright CD et al. Short and long-term outcomes after esophagectomy for cancer in elderly patients. Ann Thorac Surg 2013; 95: 1741-1748.

23. Markar SR, Karthikesalingam A, Thrumurthy $S$ et al. Systematic review and pooled analysis assessing the association between elderly age and outcome following surgical resection of esophageal malignancy. Dis Esophagus 2013; 26: 250-262.

24. Lagergren J, Bottai M, Santoni G. Patient Age and Survival After Surgery for Esophageal Cancer. Ann Surg Oncol 2021; 28: $159-166$.

25. Schlottmann F, Strassle PD, Nayyar A et al. Postoperative outcomes of esophagectomy for cancer in elderly patients. J Surg Res 2018; 229: 9-14.

26. Faiz Z, van Putten M, Verhoeven RHA et al. Impact of Age and Comorbidity on Choice and Outcome of Two Different Treatment Options for Patients with Potentially Curable Esophageal Cancer. Ann Surg Oncol 2019; 26: 986-995.

27. Ruol A, Portale G, Zaninotto G et al. Results of esophagectomy for esophageal cancer in elderly patients: age has little influence on outcome and survival. J Thorac Cardiovasc Surg 2007; 133: 1186-1192.

28. Lester SC, Lin SH, Chuong M et al. A Multi-institutional Analysis of Trimodality Therapy for Esophageal Cancer in Elderly Patients. Int J Radiat Oncol Biol Phys 2017; 98: 820-828.

29. Cooper JS, Guo MD, Herskovic A et al. Chemoradiotherapy of locally advanced esophageal cancer: long-term follow-up of a prospective randomized trial (RTOG 85 - 01). Radiation Therapy Oncology Group. JAMA 1999; 281: 1623-1627.

30. Zhao L, Zhou Y, Pan H et al. Radiotherapy Alone or Concurrent Chemoradiation for Esophageal Squamous Cell Carcinoma in Elderly Patients. J Cancer 2017; 8: 3242-3250.

31. Jingu $\mathrm{K}$, Numasaki $\mathrm{H}$, Toh $\mathrm{Y}$ et al. Chemoradiotherapy and radiotherapy alone in patients with esophageal cancer aged 80 years or older based on the Comprehensive Registry of Esophageal Cancer in Japan. Esophagus 2020; 17: $223-229$.

32. Xu C, Xi M, Moreno A et al. Definitive Chemoradiation Therapy for Esophageal Cancer in the Elderly: Clinical Outcomes for Patients Exceeding 80 Years Old. Int J Radiat Oncol Biol Phys 2017; 98: 811-819.

33. Tougeron D, Di Fiore F, Thureau S et al. Safety and outcome of definitive chemoradiotherapy in elderly patients with oesophageal cancer. Br J Cancer 2008; 99: 1586-1592.

34. Zhang P, Xi M, Zhao L et al. Is there a benefit in receiving concurrent chemoradiotherapy for elderly patients with inoperable thoracic esophageal squamous cell carcinoma? PLoS One 2014; 9: e105270.

35. Huang C, Zhu Y, Li Q et al. Feasibility and efficiency of concurrent chemoradiotherapy with a single agent or double agents vs radiotherapy alone for elderly patients with esophageal squamous cell carcinoma: Experience of two centers. Cancer Med 2019; 8: 28-39.

36. Adamson D, Byrne A, Porter $\mathrm{C}$ et al. Palliative radiotherapy after oesophageal cancer stenting (ROCS): a multicentre, open-label, phase 3 randomised controlled trial. Lancet Gastroenterol Hepatol 2021.

\section{Figures}

Page 13/18 


\section{Patients with esophageal cancer in the SEER diagnosed between 2010-2016 ( $\mathrm{N}=24006)$}

\section{Patients $<70$ years $(\mathrm{N}=7572)$}

Patients more than 70 years $(\mathrm{N}=10455)$

Patients with stage T1a,Tx,T4b,T1,NOS NA(N=6092)

Patients with stage M1 $(\mathrm{N}=743)$

Patients with stage T1b-4aNxM0 disease $(\mathrm{N}=3620)$

Other histology subtypes such as neuroendocrine carcinoma, signet ring cell carcinoma, and other malignant neoplasm( $\mathrm{N}=357)$

Potential patients with SCC or adenocarcinoma $(\mathrm{N}=3259)$

Patients receiving biopsy or aspiration (26)

Patients receiving radioactive implants or radioisotopes $(\mathrm{N}=4)$

Patients included in the study cohort $(\mathrm{N}=3233)$

Surgery $(\mathrm{N}=941)$

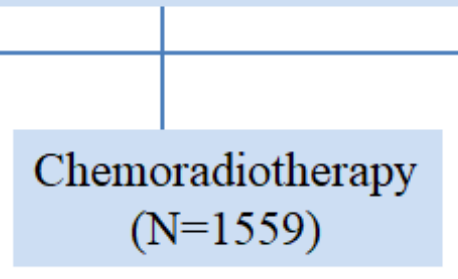

$(\mathrm{N}=1559)$

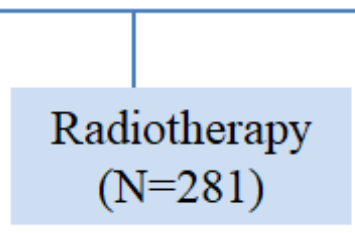

$(\mathrm{N}=281)$

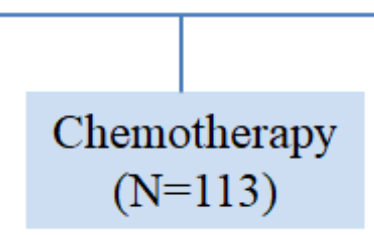

$(\mathrm{N}=113)$
Observation

$(\mathrm{N}=339)$

\section{Figure 1}

Flow chart of patient selection from the Surveillance, Epidemiology, and End Results (SEER) database. 


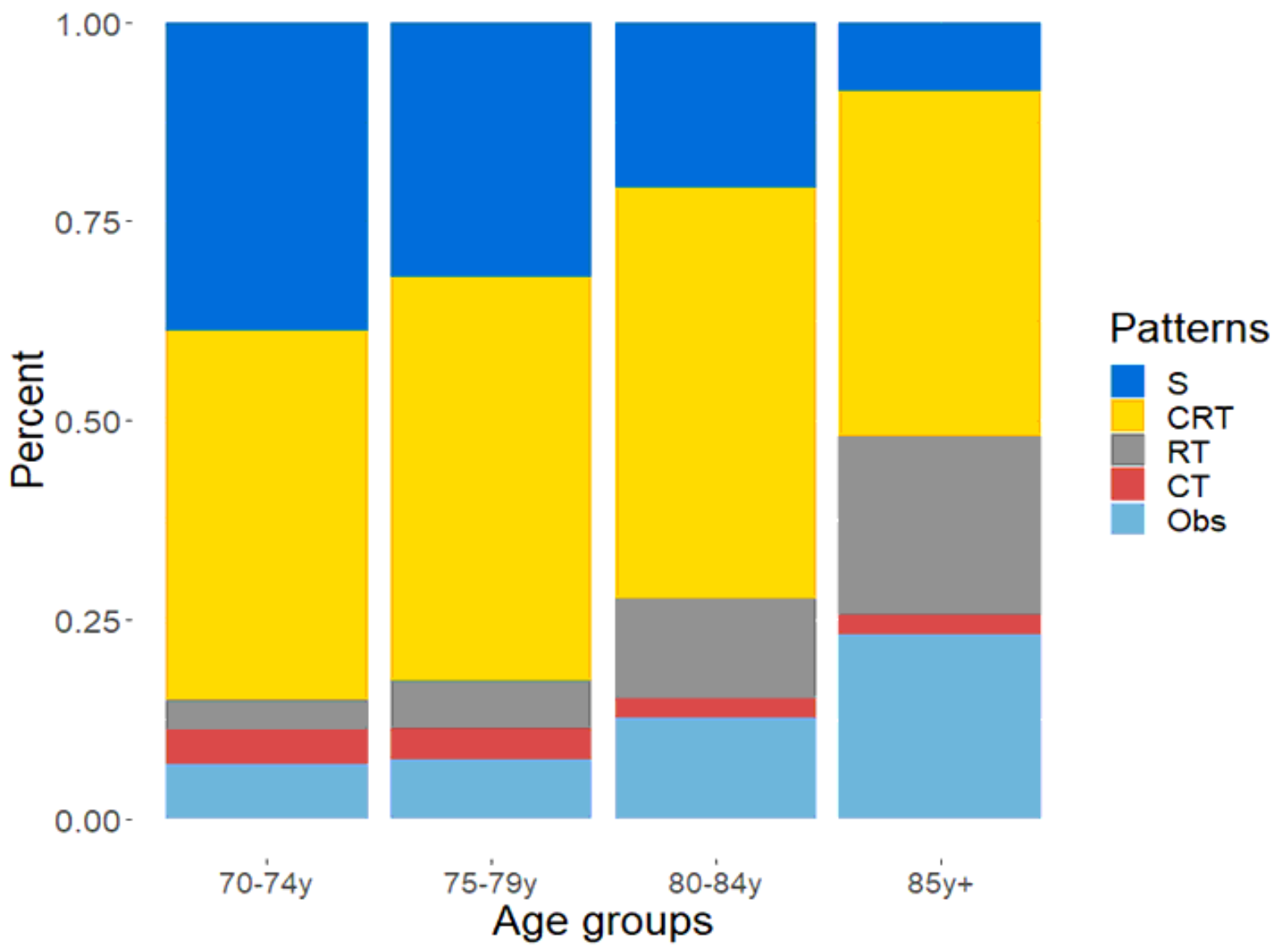

Figure 2

Treatment patterns of elderly patients with EC by age group.

A

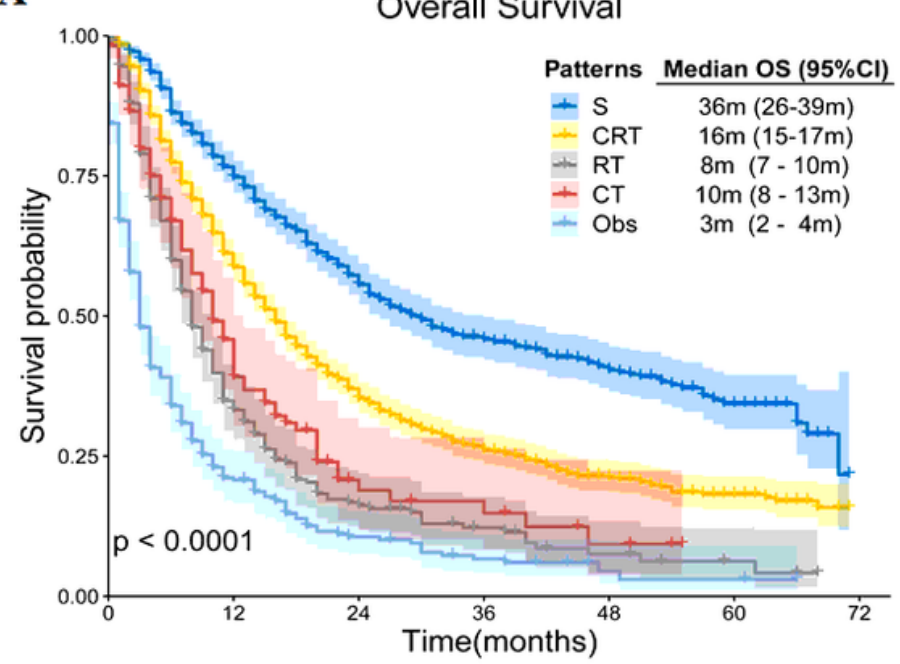

Number at risk

$\begin{array}{rcccccc}\text { S } 941 & 578 & 344 & 202 & 118 & 43 & 0 \\ \text { CRT } 1559 & 752 & 341 & 180 & 88 & 39 & 0 \\ \text { RT } 281 & 84 & 31 & 16 & 7 & 3 & 0 \\ \text { CT } 113 & 41 & 11 & 8 & 3 & 0 & 0 \\ \text { Obs } 339 & 53 & 20 & 11 & 3 & 2 & 0\end{array}$

B

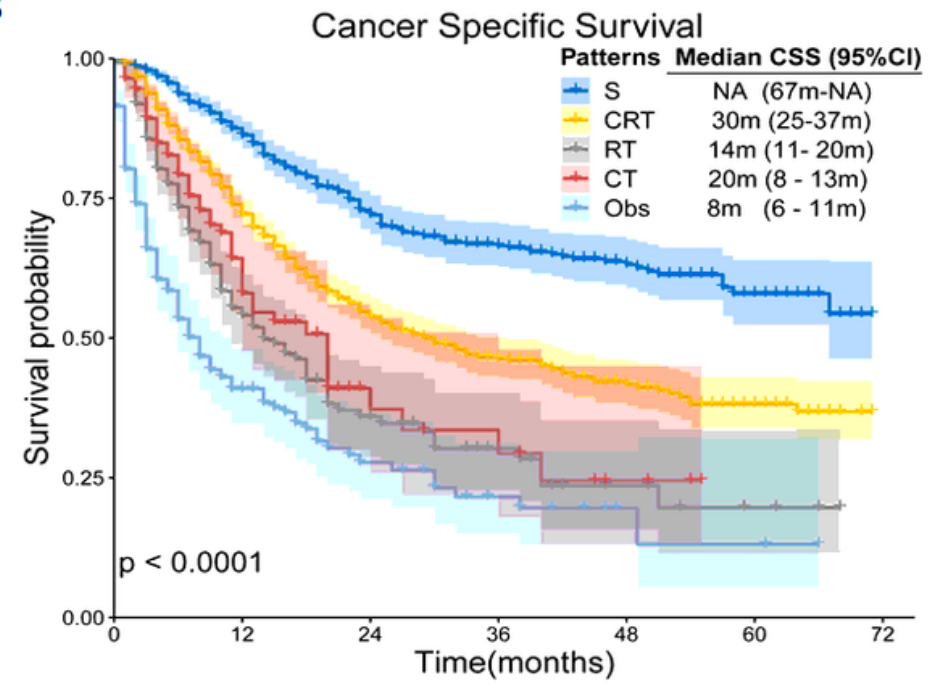

Number at risk

$\begin{array}{rcccccc}\text { S } 941 & 578 & 344 & 202 & 118 & 43 & 0 \\ \text { CRT } 1559 & 752 & 341 & 180 & 88 & 39 & 0 \\ \text { RT } 281 & 84 & 31 & 16 & 7 & 3 & 0 \\ \text { CT } 113 & 41 & 11 & 8 & 3 & 0 & 0 \\ \text { Obs } 339 & 53 & 20 & 11 & 3 & 2 & 0\end{array}$

Figure 3 
Kaplan-Meier survival curves of OS and CSS for elderly patients with potentially curable EC. (A) Overall Survival(OS), (B) Cancer Specific Survival (CSS).

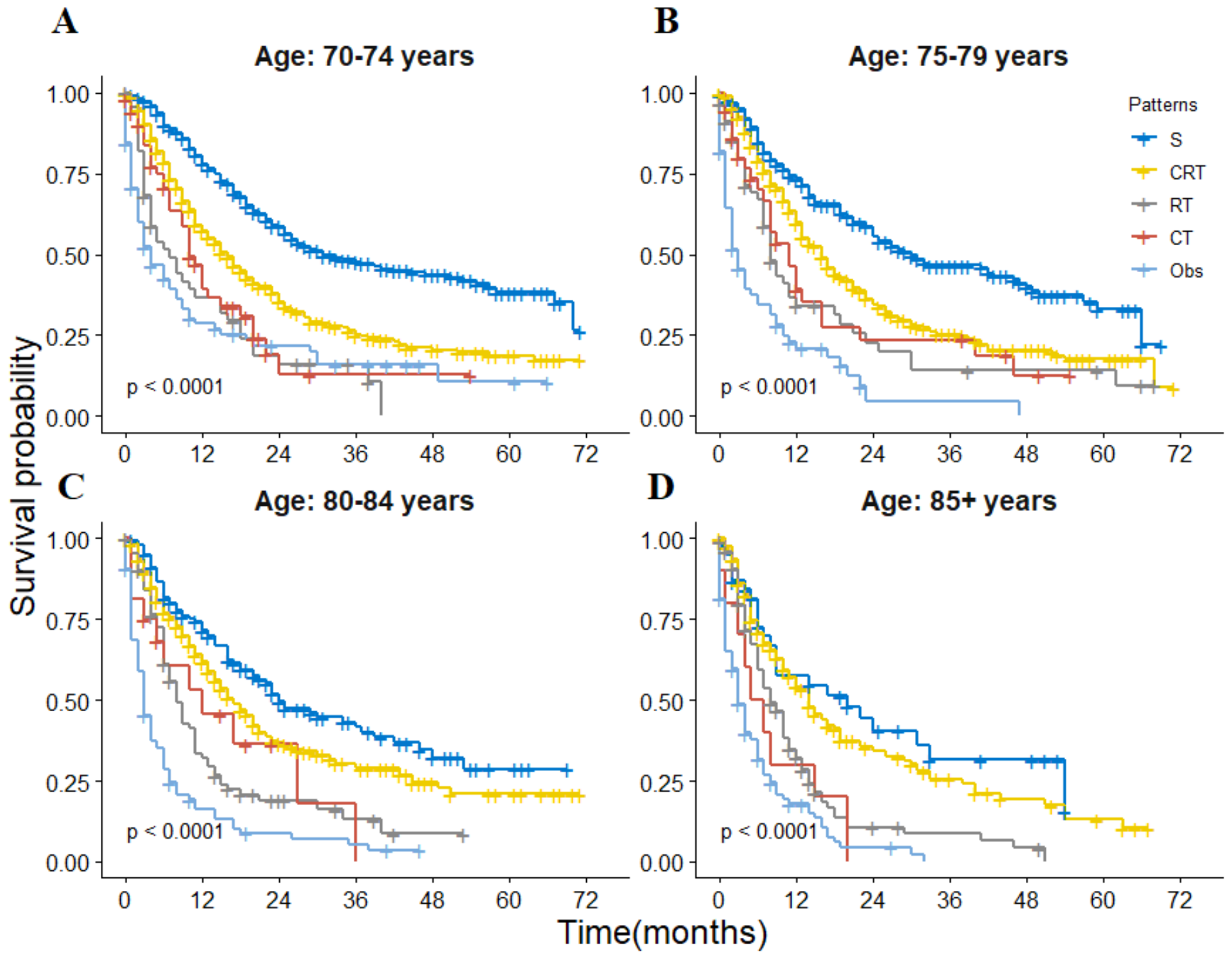

Figure 4

Kaplan-Meier survival curves of OS for elderly patients with potentially curable EC stratified by age group. (A): 70-74 year, (B)75-79 years, (C)80-84 years and (D) $\geq 85$ years. 
Points

Age

Grade

Patterns

Stage_T

Stage_N

Marital_status

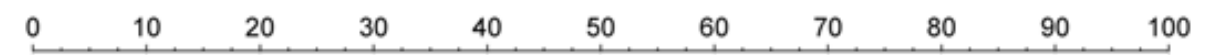

Total Points

3-Year Survival

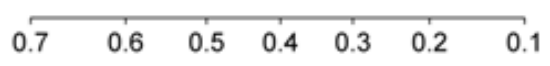

5-Year survival

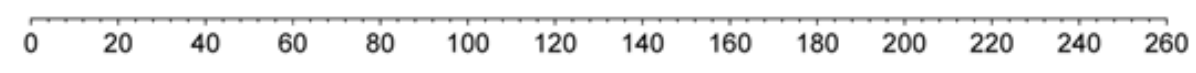

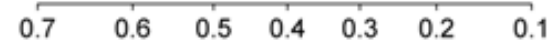

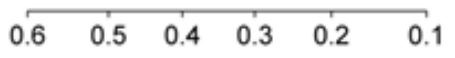

Figure 5

Nomogram for predicting 3- and 5-year probabilities of OS for elderly patients with potentially curable EC. The nomogram summed the points identified on the scale for each variable. The total points projected on the bottom scales indicate the probabilities of 3- and 5-year OS . 
A

3-year Survival AUC $=0.724$

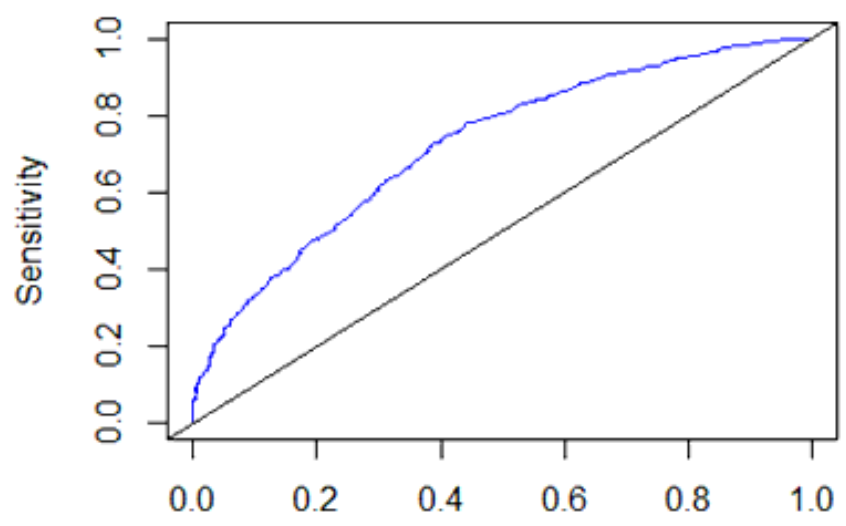

C

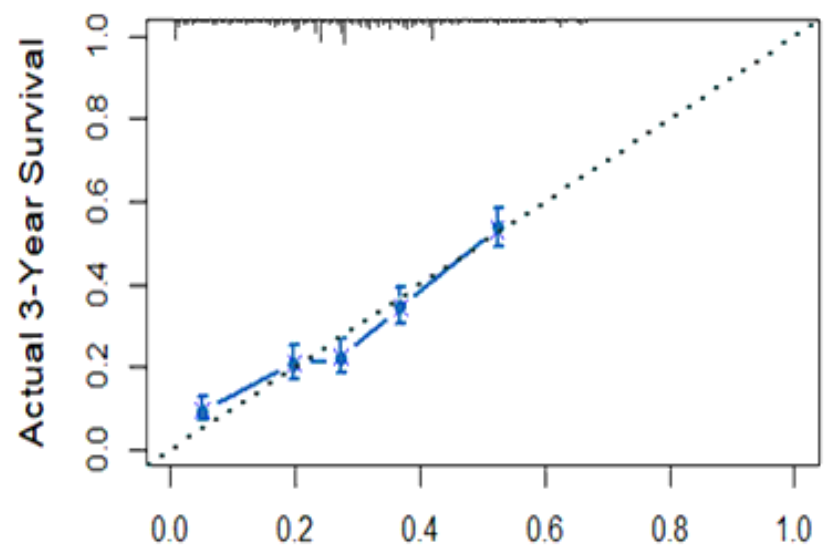

Nomogram-Predicted Probability of 3-Year Survival
B 5-year Survival AUC $=0.738$

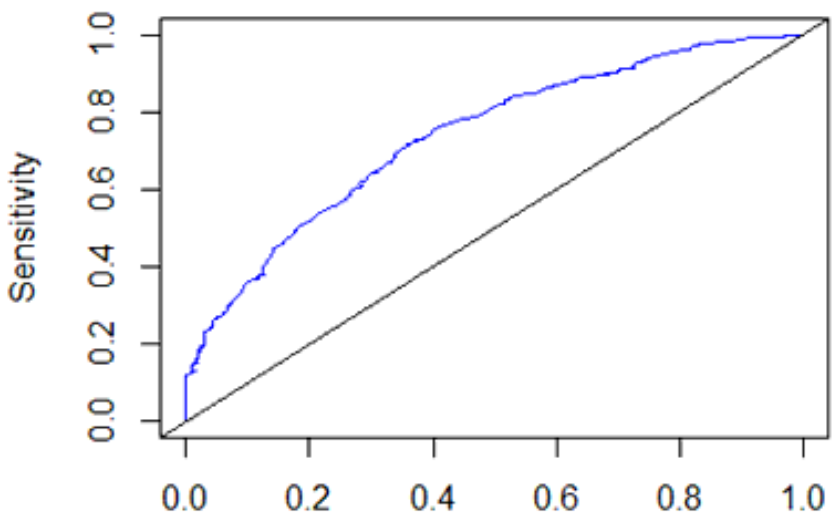

D

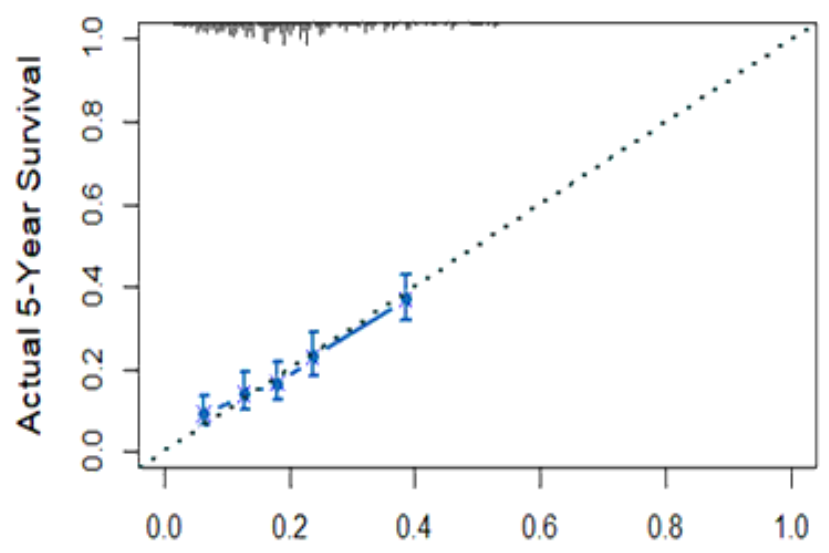

Nomogram-Predicted Probability of 5-Year Survival

\section{Figure 6}

Comparison of the AUCs and Calibration curves for the nomogram. (A-B): Area under the curves of the two models to predict overall survival at 3 years (A) and 5 years(B), (C-D): Calibration curves for the nomogram at 3 years (C) and 5 years(D), the $x$ axis represents the nomogram-predicted survival rate, whereas the y axis represents the actual survival rate.

\section{Supplementary Files}

This is a list of supplementary files associated with this preprint. Click to download.

- Tables1.docx 